Original Research Article

\title{
Drug utilization study of psychotropic drugs in psychiatry out-patient department of a tertiary care hospital in Kerala: a geriatric perspective
}

\author{
Shaikh Ubedulla S. I. D. ${ }^{1}$, Niloofar V. ${ }^{2 *}$
}

\begin{abstract}
${ }^{1}$ Department of Pharmacology, KMCT Medical College,

Calicut, Kerala, India

${ }^{2}$ Department of Global

Development, Novo Nordisk,

Bangalore, Karnataka, India
\end{abstract}

Received: 18 May 2019

Revised: 07 June 2019

Accepted: 02 July 2019

*Correspondence to:

Dr. Niloofar V.,

Email: niloofar.khader@

gmail.com

Copyright: (C) the author(s), publisher and licensee Medip Academy. This is an openaccess article distributed under the terms of the Creative Commons Attribution NonCommercial License, which permits unrestricted noncommercial use, distribution, and reproduction in any medium, provided the original work is properly cited.

\begin{abstract}
Background: Geriatrics tend to be the largest consumers of prescribed drugs exposing them to various drug interactions and adverse drug reactions. Present study is an attempt to assess the drug utilization pattern of psychotropic drugs among the geriatrics in psychiatry out-patient department (OPD) of a tertiary care hospital in Kerala.

Methods: Prescriptions of patients diagnosed with psychiatric illness and being prescribed at least one psychotropic drug were collected. Prescriptions of male and female patients of age more than 60 years were sorted and analysed separately according to WHO core prescribing indicators.

Results: $18 \%$ prescriptions were of geriatric population. Depressive disorders $(38.89 \%)$ were the most common psychiatric disorder encountered. Out of 291 drugs prescribed in geriatrics, $237(81.44 \%)$ drugs were psychotropic drugs. Among the total psychotropic drugs prescribed, antipsychotics $(39.24 \%)$ were the most commonly prescribed class of drugs. Average number of psychotropic drugs per prescription was 2.19 , drugs prescribed by generic name were $2.06 \%$ and the drugs prescribed from NLEM (2015) were 41.77\%. $86.11 \%$ of prescriptions contained more than one drug and $33.33 \%$ of prescriptions contained FDCs.

Conclusions: Prescription analysis using WHO prescribing indicators showed some deviations from the standard which can be improved. A trend of polypharmacy was noted in this study. Prescribing using generic name and prescribing from NLEM was low as compared to the other reference studies. Proper strategies taken to overcome the inadequacies pointed out by this study can ensure the rational use of medicines.
\end{abstract}

Keywords: Drug utilization, Geriatrics, Psychotropic drugs, WHO prescribing indicators.

\section{INTRODUCTION}

Drug utilization study is defined as the study of marketing, distribution and prescription of various drugs in society, along with evaluation of its medical, social, and economic consequences. ${ }^{1}$ World Health Organisation (WHO) and International Network for Rational Use of Drugs (INRUD) have recommended the use of standard drug use indicators which help us to know the shortcomings in prescription writing. ${ }^{2}$ Geriatrics represent the most vulnerable section of our society and tend to be the largest consumers of prescribed drugs. ${ }^{3}$ It is predicted that the population of geriatrics in our country will rise from $7.5 \%$ in 2010 to $11.1 \%$ in 2025 due to increase in life expectancy. ${ }^{4}$ The various issues faced in the medication management of the elderly population are polypharmacy that directly or indirectly leads to drug interactions and adverse drug reactions, poor patient compliance as well as 
pharmacokinetic and pharmacodynamics changes that occurs in elderly. ${ }^{3}$

Since 1950s, psychotropic drugs have proliferated, and diagnosed cases have also increased. In this way, psychiatrists are continuously exposed to newly introduced drugs that are claimed to be safe and more efficacious. ${ }^{5}$ There is an increased use of psychotropic drugs in geriatric population as over $20 \%$ of them suffer from a mental or neurological disorder (excluding headache disorders). ${ }^{6}$ Monitoring of prescription pattern help us to describe the current prescribing behaviour, identify the factors responsible for the practice of polypharmacy and the problems associated with it and provide feedback to the prescribers so as to so as to make medical care rational and cost-effective. ${ }^{7}$

With this background, the present study is an attempt to assess the drug utilization pattern of psychotropic drugs among the geriatrics in psychiatry out-patient department (OPD) of a tertiary care hospital in Kerala.

\section{METHODS}

This was a cross sectional observational study conducted in the psychiatry out-patient department of our centre at Kerala over a period of 6 months. The study was conducted after getting approval from the institutional ethics committee. A total of 600 prescriptions of patients diagnosed with psychiatric illness and being prescribed at least one psychotropic drug were collected randomly after obtaining written informed consent. Out of these, prescriptions of male and female patients of age more than 60 years were sorted and analysed separately for the following parameters

- Demographic pattern

- Distribution of the various psychiatric disorders.

- Pattern of psychotropic drug use.

- WHO core prescribing indicators: Average number of drugs per encounter, percentage of drugs prescribed by generic name, percentage of encounters with an injection prescribed and percentage of drugs prescribed from essential drugs list.

- Percentage of prescriptions with more than 1 drug

- Percentage of prescriptions containing Fixed dose combinations (FDC).

Data was entered and analyzed in Microsoft Excel. Results were expressed in terms of frequency and percentage distribution.

\section{RESULTS}

Out of the 600 prescriptions collected, 108 (18\%) prescriptions were of geriatric population. Total number of drugs prescribed in geriatric group was 291 out of which 237 were psychotropic drugs. Gender and age characteristics of study participants are shown in tables 1 and 2 respectively. Out of 108 prescriptions studied,
$60(55.56 \%)$ belong to females and the rest $48(44.44 \%)$ belong to males, showing a slight female preponderance. Maximum number of prescriptions were seen in the age group of $61-70$ years $(72.22 \%)$ followed by $71-80$ years $(25.00 \%)$. Only $2.78 \%$ of prescriptions were at the age group of 81-90 years.

Table 1: Gender wise distribution of geriatric patients attending the psychiatry OPD.

\begin{tabular}{|lll|}
\hline Gender & No. of patients & Percentage (\%) \\
\hline Male & 48 & 44.44 \\
\hline Female & 60 & 55.56 \\
\hline
\end{tabular}

Table 2: Age wise distribution of geriatric patients attending the psychiatry OPD.

\begin{tabular}{|lll|}
\hline Age group (in years) & No. of patients & $\%$ \\
\hline $61-70$ & 78 & $72.22 \%$ \\
\hline $71-80$ & 27 & $25.00 \%$ \\
\hline $81-90$ & 03 & $02.78 \%$ \\
\hline
\end{tabular}

Distribution of various psychiatric disorders among the study population (figure 1) showed that, depressive disorders $(38.89 \%) \quad(n=42)$ were the most common disorder encountered followed by schizophrenia and other psychotic disorders $(30.56 \%)(\mathrm{n}=33)$, bipolar and related disorders $(19.44 \%)(\mathrm{n}=21)$ and anxiety disorders $(5.56 \%)$ $(n=6)$. The remaining prescriptions were categorized as other psychiatric illnesses $(5.56 \%)(n=6)$.

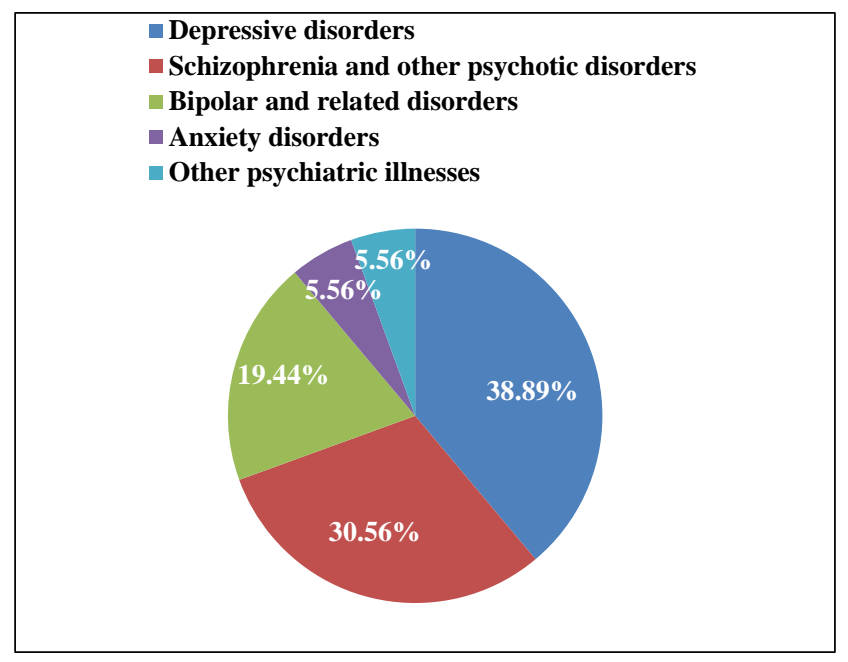

Figure 1: Distribution of various psychiatric disorders among the study population.

Analysis of prescription pattern according to the WHO core prescribing indicators is shown in table 3. 108 geriatric prescriptions were analyzed containing a total of 291 drugs. Out of these $81.44 \% \quad(n=237)$ were psychotropic drugs. The number of drugs in a prescription varied from 1-7 with an average of 2.69. The average number of psychotropic drugs per prescription was 2.19. Out of the total 291 drugs prescribed, only $2.06 \%$ of the 
drugs were prescribed by generic name and only $0.03 \%$ of prescriptions contained injections. $41.77 \%$ of psychotropic drugs were prescribed from NLEM (2015) and 17.72\% from the WHO model list of essential medicines (2017).

Table 3: Assessment of prescription pattern as per the WHO core prescribing indicators.

\begin{tabular}{|ll|}
\hline WHO core prescribing indicator & Result \\
\hline Average number of drugs per encounter & 2.69 \\
\hline $\begin{array}{l}\text { Percentage of drugs prescribed by } \\
\text { generic name }\end{array}$ & $\begin{array}{l}2.06 \% \\
(\mathrm{n}=6)\end{array}$ \\
\hline $\begin{array}{l}\text { Percentage of encounters with an } \\
\text { antibiotic prescribed }\end{array}$ & $0.00 \%$ \\
\hline $\begin{array}{l}\text { Percentage of encounters with an } \\
\text { injection prescribed }\end{array}$ & $\begin{array}{l}0.03 \% \\
(\mathrm{n}=3)\end{array}$ \\
\hline $\begin{array}{l}\text { Percentage of psychotropic drugs } \\
\text { prescribed from NLEM (2015) }\end{array}$ & $\begin{array}{l}41.77 \% \\
(\mathrm{n}=99)\end{array}$ \\
\hline $\begin{array}{l}\text { Percentage of psychotropic drugs } \\
\text { prescribed from WHO model list of } \\
\text { essential medicines (2017) }\end{array}$ & $\begin{array}{l}17.72 \% \\
(\mathrm{n}=42)\end{array}$ \\
\hline
\end{tabular}

All the psychotropic drugs prescribed were categorized into 4 broad classes i.e. antidepressants, antipsychotics, anxiolytics and antimanic/mood stabilizers as shown in table 4. Among the total psychotropic drugs prescribed, antipsychotics $(39.24 \%)$ were the most commonly prescribed class of drugs followed by antidepressants (31.65\%), anxiolytics $(20.25 \%)$ and antimanic/ mood stabilizers $(8.86 \%)$.

Table 4: Classes of psychotropic drugs prescribed among the study population.

\begin{tabular}{|lll|}
\hline Psychotropic drug class & $\begin{array}{l}\text { Number of } \\
\text { drugs }\end{array}$ & $\%$ \\
\hline Antipsychotics & 93 & $39.24 \%$ \\
\hline Antidepressants & 75 & $31.65 \%$ \\
\hline Anxiolytics & 48 & $20.25 \%$ \\
\hline Antimanic/Mood stabilizers & 21 & $08.86 \%$ \\
\hline Total & 237 & $100 \%$ \\
\hline
\end{tabular}

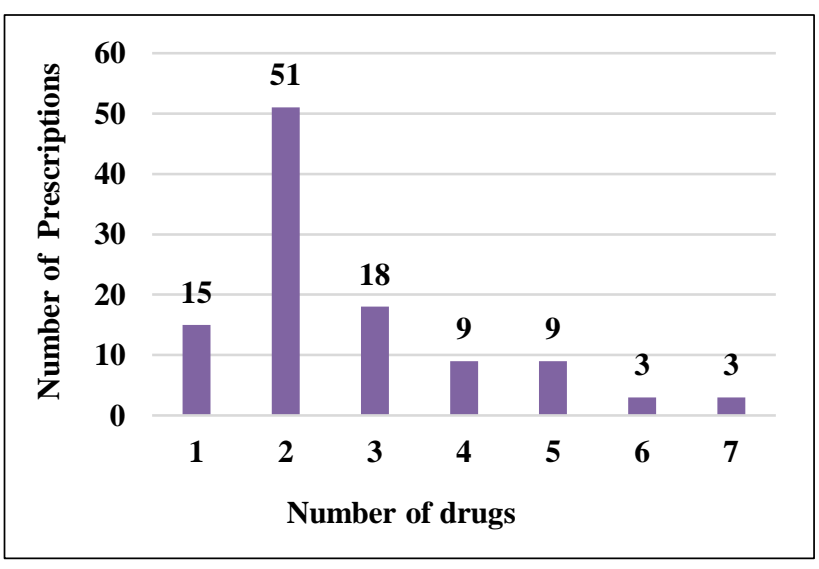

Figure 2: Number of drugs prescribed per prescription.
Out of the total 108 prescriptions, only 15 prescriptions $(13.89 \%)$ were prescribed with one drug whereas 93 prescriptions $(86.11 \%)$ contained more than one drug. Majority of the prescriptions were prescribed with 2 drugs (47.22\%), followed by 3 drugs (16.67\%), 1 drug (13.89\%), 4 drugs (8.33\%), 5 drugs (8.33\%), 6 drugs (2.77\%) and 7 drugs $(2.77 \%)$ as shown in figure 2 .

Out of the total 108 geriatric prescriptions analyzed, 36 prescriptions $(33.33 \%)$ contained FDCs. Out of the total drugs prescribed, $13.4 \%$ were FDCs (figure 3). Most commonly prescribed FDC was combination of Risperidone and Trihexyphenidyl.

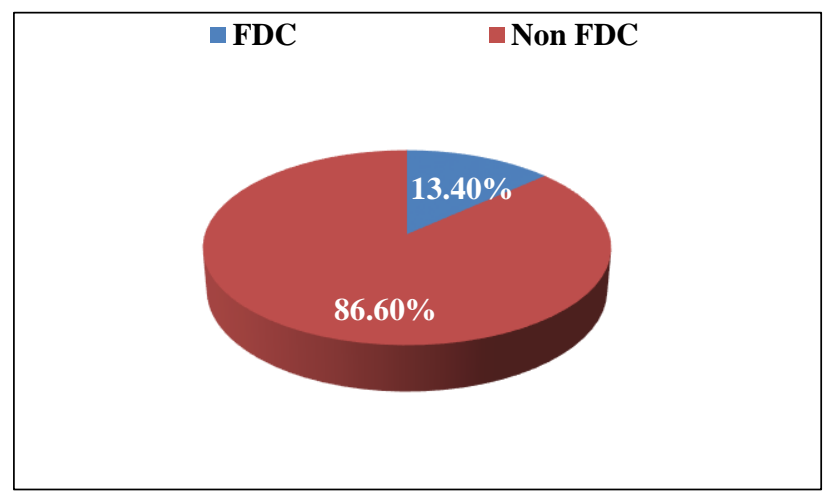

Figure 3: Percentage utilization of FDCs.

\section{DISCUSSION}

In this study more female patients visited the psychiatry OPD than men. The percentage of male and female patients are $44.44 \%$ and $55.56 \%$ respectively. This finding is similar to the findings of study done by Nandagopal et al. ${ }^{8}$ Majority of the patients were in the age group of 61-70 years which was found similar to the study conducted by Bhaveshaikh et al. $^{3}$ Patients with depressive disorders accounted for large majority $(38.89 \%)$ of the patients attending the psychiatric OPD followed by schizophrenia and other psychotic disorders $(30.56 \%)$ which is comparable to other studies done in India. ${ }^{9,10}$ Analysis of prescription pattern as per the WHO prescribing indicators showed that the average number of drugs per prescription in this study was 2.69. This number is much lesser than that observed in other similar studies where it ranged from 3.8 to 7.02 . Higher number of drugs per encounter can increase the risk of drug interactions, dispensing errors, patient not knowing correct dosage schedule, patient noncompliance and increased cost. ${ }^{11}$ Out of the total 291 drugs prescribed only $2.06 \%$ of the drugs were prescribed by generic name which is much less when compared to the WHO standards. ${ }^{8}$ WHO highly recommends prescribing medications by generic name as a safety precaution for patients because it identifies the drug clearly, enables better information exchange and allows better communication between health care providers. ${ }^{12}$ Prescribing by generic names also decrease the cost of treatment which is important for a country like India which faces cost restraints due to low socioeconomic status of 
most of our patients. ${ }^{11}$ Giving drugs in the form of injections is not a common practice in psychiatry, barring emergency situations. The percentage of encounters with an injectable prescribed in this study was only $0.03 \%$ when compared to study done by Nandagopal et al. ${ }^{8}$ In this study out of the total 237 psychotropic drugs, $41.77 \%$ of psychotropic drugs were prescribed from NLEM (2015) and $17.72 \%$ from the WHO model list of essential medicines (2017). Compared to other reference studies, the percentage of drugs prescribed from EML was lower in the present study. ${ }^{13}$ Thus there is a need for increasing access to essential medicines for promoting rational use of medicines. Among the psychotropic drugs prescribed, antipsychotic drugs were more frequently prescribed class of drugs $(39.24 \%)$ in this psychiatry OPD. Similar finding was observed in a study of prescribing pattern of psychotropic drugs done by Jena et al. ${ }^{5}$

In this study, $86.11 \%$ of the prescriptions contained more than one drug showing a trend towards polypharmacy. This is in line with the study conducted by Fadare et al. ${ }^{14}$ Polypharmacy can lead to poor compliance, drug interactions, adverse drug reactions, under-use of effective treatments and medication errors. The reason for polypharmacy in this study may be attributed to the complexity of presentation in psychiatric illness and the presence of multiple comorbidities in the elderly.

In the present study $33.33 \%$ of prescriptions contained FDCs. Out of the total drugs prescribed, $13.4 \%$ were prescribed as FDCs which is less when compared to study done by Kohle et al. ${ }^{13}$ Most commonly prescribed FDC was combination of Risperidone $2 \mathrm{mg}+$ Trihexyphenidyl $2 \mathrm{mg}$. Routine use of anticholinergic drugs like trihexyphenidyl can be debilitating as it results in side effects like retention of urine, constipation, attack of angle closure glaucoma, dry mouth etc. Based on a number of studies, the WHO has recommended that anticholinergics should not be used routinely for preventing extrapyramidal symptoms in individuals with psychotic disorders treated with antipsychotics but used only for short term in selected cases. ${ }^{15}$ Overall FDCs have their own advantages and disadvantages which need to be taken into consideration on a patient to patient basis.

\section{CONCLUSION}

Prescription analysis using WHO prescribing indicators showed some deviations from the standard which can be improved. A trend of polypharmacy was noted in this study. The incidence of polypharmacy should be minimized as it might result in poor compliance, increased drug interactions, and side effects. The reason for polypharmacy in this study may be attributed to the complexity of presentation in psychiatric illness and the presence of multiple comorbidities in the elderly. The present study also showed that percentage of drugs prescribed using generic name was low as compared to the other reference studies. This may be due to concern of prescribers regarding safety and efficacy of drugs.
Prescription of drugs in their generic names leads to improved patient compliance and less financial burden contrary to the use of brand names. Thus, our study suggests a strong need for creating awareness in the prescribers regarding the usage of generic names. Drugs prescribed from EML was less than the other reference studies indicating need to increase the usage of drugs from EML, adequate supply of drugs at health facilities, making copies of NLEM available, sensitization for prescribers regarding use of drugs from NLEM. The present study also emphasised on FDC usage pattern. As an opinion single medicines are preferred over FDCs unless they are proved to be rational with confirmed advantage. In this study the percentage use of FDCs were comparatively low.

Hence the proper strategies taken to overcome the inadequacies pointed out by this study can ensure the rational use of medicines. There is also considerable scope to extend this study by evaluating drug compliance and adverse drug reactions of psychotropic drugs.

\section{ACKNOWLEDGEMENTS}

Authors acknowledge all the participants for sparing their valuable time for betterment of patient care.

\section{Funding: No funding sources}

Conflict of interest: None declared

Ethical approval: The study was approved by the Institutional Ethics Committee

\section{REFERENCES}

1. World Health Organization. How to investigate Drug use in health Facilities; selected drug use indicators, WHO/DAP/93. 1993;1:1-87.

2. Durga P, Abhinav P, VarunRaj K, Kishore P. Evaluation of prescribing patterns using WHO indicators at out-patient department of a private hospital in Warangal. IOSR J Pharm and Biol Sci 2017;12(3):1-4.

3. Bhaveshaikh N, Sukumaran S, Vyas U. Drug prescribing patterns in elderly patients in a tertiary level hospital. Int $\mathrm{J}$ Basic Clin Pharmacol. 2017;6(4):759-64.

4. Mane AB. Ageing in India: some social challenges to elderly care. J Gerontol Geriatr Res. 2016 Feb 2;5(2):e136.

5. Jena M, Mishra S, Mishra SN, Mishra SS. Psychotropic drugs: Prescribing pattern in psychiatry outpatient department of a tertiary care teaching hospital. Int J Pharm. 2014;4(4):204-8.

6. World Health Organization. Mental health and older adults. Available at: http://www.who.int/mediacentre/factsheets/fs381/en/. Accessed 2019 Jan 26.

7. Mukherjee S, Sen S, Chatterjee SS, Biswas A, Sinha S, Ghosal M, et al. Prescribing Pattern of Psychotropic Medications in Psychiatry Outpatients at a Tertiary Care Teaching Hospital in India: A Prospective Cross- 
sectional Study. Int J Hosp Res. 2014 Sep 1;3(3):11322.

8. Nandagopal A, Koneru A, Rahman A, Pasha MK, Ali MK. Assessment of rational drug prescribing pattern in geriatric patients in hyderabad metropolitan. Ind $\mathbf{J}$ Pharm Pract. 2017 Jul;10(3):175-8.

9. Shaktibala D, Atif BM, Vijay K, Srihari D. Psychotropic drug utilization study in psychiatric OPD of a tertiary care teaching hospital in Dehradun, Uttarakhand. J of Adv Res Biol Sci. 2013;5(4):386-91.

10. Doshi CM, Hedamba R, Darji NH, Patel B, Trivedi HR, Tiwari D. Drug utilization study of psychotropic drugs in outdoor patients in a tertiary care hospital attached with a medical college. Int $\mathrm{J}$ Basic \& Clin Pharm. 2015;4:1220-23.

11. Chawla S, Agarwal M, Sharma S, Jiloha RC. Drug Utilization Study of Psychotropic Drugs among Psychiatric Outpatients in a Tertiary Care Hospital. Indian J Pharm Sci. 2018 Jan 30;79(6):1008-13.

12. El Mahalli AA, Akl OA, Al-Dawood SF, Al-Nehab AA, Al-Kubaish HA, Al-Saeed S, et al. WHO/INRUD drug prescribing indicators at primary health care centres in Eastern province, Saudi Arabia. East Mediterr Health J. 2012;18(11):1086-90.
13. Kohle A, Kale AS, Padwal SL. Drug utilization study in geriatric patients at rural tertiary care hospital. Asian J Pharm Clin Res 2015;8(4):90-2.

14. Fadare JO, Agboola SM, Opeke OA, Alabi RA. Prescription pattern and prevalence of potentially inappropriate medications among elderly patients in a Nigerian rural tertiary hospital. Therapeutics and clinical risk management. 2013;9:115-20.

15. Thakkar KB, Jain MM, Billa G, Joshi A, Khobragade AA. A drug utilization study of psychotropic drugs prescribed in the psychiatry outpatient department of a tertiary care hospital. Journal of clinical and diagnostic research: JCDR. 2013 Dec;7(12):2759-64.

Cite this article as: Ubedulla SSID, Niloofar V. Drug utilization study of psychotropic drugs in psychiatry out-patient department of a tertiary care hospital in Kerala: A geriatric perspective. Int J Basic Clin Pharmacol 2019;8:1788-92. 